This is a self-archived version of an original article. This version may differ from the original in pagination and typographic details.

Author(s): Silinskas, Gintautas; Torppa, Minna; Lerkkanen, Marja-Kristiina; Nurmi, Jari-Erik

Title: The home literacy model in a highly transparent orthography

Year: 2020

Version: Accepted version (Final draft)

Copyright: (c) 2019 Informa UK Limited, trading as Taylor \& Francis Group

Rights: In Copyright

Rights url: http://rightsstatements.org/page/InC/1.0/?language=en

Please cite the original version:

Silinskas, G., Torppa, M., Lerkkanen, M.-K., \& Nurmi, J.-E. (2020). The home literacy model in a highly transparent orthography. School Effectiveness and School Improvement, 31(1), 80-101. https://doi.org/10.1080/09243453.2019.1642213 
The Home Literacy Model in a Highly Transparent Orthography 


\begin{abstract}
We investigated the extent to which home literacy activities during the preschool year would predict the development of children's language and literacy skills in primary school, in a highly transparent Finnish language. Also, the correlates of maternal literacy activities during preschool were examined. Literacy and language skills of 1,880 children (6-year-olds at a baseline) were tested at five time-points from the beginning of preschool to the end of Year 2; mothers filled in questionnaires at the end of preschool. The results showed that home teaching of reading at preschool age predicted children's emergent literacy (letter knowledge, word reading fluency) in primary school, while shared reading predicted oral language skills (vocabulary, listening comprehension). Moreover, early letter knowledge was related to both the maternal teaching of reading and shared reading, while maternal beliefs and expectations about their children's schooling and competence were associated with more frequent engagement in the teaching of reading.
\end{abstract}

Keywords: home literacy, teaching of reading, shared reading, parental beliefs, literacy 
The Home Literacy Model in a Highly Transparent Orthography

The Home Literacy Model (HLM; Sénéchal \& LeFevre, 2002, 2014) postulates that children are exposed to two types of literacy activities at home, that is, formal and informal activities, and that these types of activities are differentially related to children's literacy and language skills. In opaque languages, that is, languages that are characterized by inconsistent phoneme-grapheme correspondence, such as English (Sénéchal, LeFevre, Thomas, \& Daley, 1998; Sénéchal \& LeFevre, 2002) and French (Sénéchal, 2006), formal literacy activities (e.g., teaching reading) have been found to promote written language-related skills (e.g., emergent literacy skills), whereas informal reading activities (e.g., shared reading) are beneficial for oral language related skills (e.g., vocabulary). The model has also received support in more transparent languages, such as German (Lehrl, Ebert, \& Roßbach, 2013; Niklas \& Schneider, 2013, 2017), Greek (Manolitsis, Georgiou, Parrila, 2011; Manolitsis, Georiou, \& Tziraki, 2013) and Spanish (Farver, Xu, Lonigan, \& Eppe, 2013). However, only a limited number of studies have been conducted that focus on the developmental links between HLM and reading skills in highly transparent orthographies, and little research has been conducted on the relations between HLM and reading development from preschool to primary school outcomes. Therefore, the present longitudinal study investigated the extent to which the Home Literacy Model could be replicated among children learning to read Finnish, a language characterized by a highly transparent orthography. To this end, we examined, firstly, the extent to which the HLM during preschool (i.e., the maternal teaching of reading and shared reading) predicts the development of children's language and literacy skills among Finnish primary school children, and secondly, a range of possible correlates of the maternal teaching of reading and shared reading during the preschool year.

\section{The Home Literacy Model}


According to the Home Literacy Model (Sénéchal, 2006; Sénéchal \& LeFevre, 2002, 2014; Sénéchal et al., 1998), formal literacy activities are defined as activities that focus on print per se (e.g., teaching letter names, sounds, or reading) which, it is suggested, are directly related to children's literacy skills (e.g., print concepts, letter knowledge, invented spelling, decoding; Sénéchal \& LeFevre, 2002; Torppa, Poikkeus, Laakso, Eklund, \& Lyytinen, 2006). Informal literacy activities, on the other hand, are those where print is present in parent-child interaction but is not its focus (e.g., making children's books available, shared reading; Burgess, Hecht, \& Lonigan, 2002; Bus, van IJzendoorn, \& Pellegrini, 1995; Davidse, de Jong, Bus, Huijbregts, \& Swaab, 2011; Roberts, Jurgens, \& Burchinal, 2005; Scarborough \& Dobrich, 1994). According to the HLM, formal literacy activities enhance reading fluency through mastering decoding, whereas informal literacy activities increase reading comprehension through language development (e.g., vocabulary).

Although the HLM was created in the context of orthographically opaque languages, such as English and French (Hood, Conlon, \& Andrews, 2008; Levy, Gong, Hessels, Evans, \& Jared, 2006; Sénéchal \& LeFevre, 2002, 2014; Stephenson, Parrila, Georgiou, \& Kirby, 2008), the model has also been applied to some orthographically transparent languages (e.g., German: Lehrl et al., 2013; Niklas \& Schneider, 2013, 2017; Greek: Manolitsis et al., 2011, 2013; Spanish: Farver et al., 2013). There has, however, been little systematic investigation of almost fully transparent languages, such as Finnish (for the few exceptions, see Silinskas et al., 2010, 2012, and Torppa et al., 2006, 2007). The orthographic characteristics of the language may act to the learner's advantage or disadvantage. For instance, although the English language contains a high proportion of short words, the irregularity of the orthography burdens reading acquisition (Seymour, Aro, Erskine, 2003; Ziegler \& Goswami, 2005; Ziegler et al., 2010). In contrast, in Finnish, learning to read is much easier, as the language is characterized by unusually regular orthography; there is highly consistent letter- 
sound correspondence in which each letter stands only for one sound (Seymour et al., 2003). For this reason, Finnish children learn to decode very rapidly: Around $30 \%$ of children learn to decode before entering Year 1, and almost all children master decoding in their first six months at school (Lerkkanen, Rasku-Puttonen, Aunola, \& Nurmi, 2004; Soodla et al., 2015). Unfortunately, no studies have directly compared the strength of the associations between parental home literacy activities and child literacy and language development in languages varying in the transparency of their orthography. However, the fact that reading acquisition in transparent orthographies is much faster suggests that in transparent orthographies, such as Finnish, the role of parental literacy and language activities at home might be related to children's literacy skills to a lesser degree than in less transparent language contexts. Consequently, testing the HLM in the highly orthographically transparent Finnish language was one of the aims of the current study.

\section{Emergent Literacy Skills and Home Literacy Activities}

While it is widely acknowledged that parental involvement in home literacy contributes to children's literacy and language outcomes, children's characteristics (i.e., emergent literacy skills) may also direct their parents' behavioural responses (Levin et al., 1997; Pomerantz \& Eaton, 2001; Scarr \& McCartney, 1983). The term “evocative effect" refers to adults' responses arising from their children's characteristics, such as academic performance or socio-emotional responses (Scarr \& McCartney, 1983). Previous research on parents' involvement has shown that among school-aged children the child's academic skills and achievement evoke their parents' academic involvement (Levin et al., 1997; Pomerantz \& Eaton, 2001; Silinskas et al., 2012). However, the evocative effect of children's emergent literacy skills at the age when they attend preschool has been much less examined. Consequently, the present study investigated also the role of children's emergent literacy skills as possible correlates of subsequent parental involvement. 


\section{Parental Beliefs, Expectations and Home Literacy Activities}

The frequency with which parents engage in home literacy activities may also derive from certain parental beliefs and expectations about children's schooling and competences. The most often investigated parental beliefs include their views on the importance of literacy (Kluczniok, Lehrl, Kuger, \& Rossbach, 2013; Martini \& Sénéchal, 2012; Sénéchal \& LeFevre, 2014; Skwarchuk, Sowinski, \& LeFevre, 2014), their beliefs about their children's competence in a particular skill (Aunola, Nurmi, Niemi, Lerkkanen, \& Rasku-Puttonen, 2002; Frome \& Eccles, 1998), and their beliefs and expectations for their children's overall school performance (Mägi, Lerkkanen, Poikkeus, Rasku-Puttonen, \& Nurmi, 2011; Stephenson et al., 2008; Storch \& Whitehurst, 2001). By studying beliefs that parents hold about their children's ability and schooling, we get a more comprehensive picture of why parents get engaged into home literacy activities. In practical terms, by promoting certain type of beliefs, we may encourage or discourage parents to engage into home literacy activities with their children.

The belief about the importance of literacy readiness is one among many parental views concerning what skills are important for their children to know before they start formal reading instruction (Sénéchal \& LeFevre, 2014). This belief has been shown to be related to parental teaching of reading before school entrance (e.g., Martini \& Sénéchal, 2012; Skwarchuk et al., 2014) and overall familial promotion of literacy in terms of availability of children's books, frequency of shared book reading and stimulation to learn alphabet and reading (Kluczniok et al., 2013). Also, this belief of importance of literacy before school entrance was shown to predict emergent literacy skills at the beginning of Year 1 (Sénéchal \& LeFevre, 2014).

There is also some evidence to suggest that parents who have higher expectations concerning their children's performance may be more involved in their children's educational 
process (Davis-Kean, 2005). However, the role of parental beliefs and expectations with regard to children's competences is most often investigated among parents of children in primary school (Aunola et al., 2002; Mägi et al., 2011) or older children/adolescents (Frome \& Eccles, 1998; Stevenson \& Newman, 1986). Thus, there is a need for research focusing on the link between parental beliefs and expectations and their home literacy activities while their children are in preschool, before formal literacy instruction starts. We hypothesized that parents with positive beliefs and expectations about children's schooling and competences would also be more involved in home literacy activities with their children.

\section{Education in Finland}

In Finland, compulsory education begins in the August of the year that the child has her/his seventh birthday. A year before, each child is eligible to attend preschool. The goals of the preschool curriculum focus on fostering children's personal and social development rather than formally teaching academic skills. However, children are read to and encouraged to play with letters, words, and numbers during their activities there (Lerkkanen, 2004; Soodla et al., 2015). The curriculum for Year 1 focuses on learning to decode syllables and words, and practicing fluency and comprehension. Student gains in reading are encouraged by the availability of high-interest texts at multiple levels of difficulty and by giving pupils the freedom to choose their own reading materials (Lerkkanen et al., 2004; Soodla et al., 2015).

\section{The Present Study}

The present longitudinal study tested the extent to which the Home Literacy Model (HLM; Sénéchal \& LeFevre, 2002, 2014) can be replicated in the context of the highly transparent Finnish orthography. It also sought to expand the HLM by investigating possible correlates of parental home literacy activities. The following research questions guided our longitudinal investigation: 
(1) To what extent does the home learning environment at preschool age predict the development of children's literacy and language skills at primary school (Years 1 and 2) in the highly transparent Finnish orthography? Based on HLM, we expected that formal literacy activities — the teaching of reading — would promote skills related to the written language, while informal reading activities_-shared reading—would promote oral language skills. Because of the highly transparent orthography, children's reading acquisition in Finland is exceptionally rapid. Thus, we hypothesized that home literacy activities in the preschool year would show an expected but weak association with reading. The associations between home literacy activities and literacy and language skills might be weak because of the transparency of the language and effective Year 1 reading instruction, which makes possible the rapid acquisition of reading skills during Year 1.

(2) To what extent would children's emergent literacy skills (i.e., phonological skills and letter knowledge) and maternal beliefs and expectations about schooling and competences (e.g., the importance of literacy readiness in preschool, or expectations for their children's success in literacy tasks and school performance) relate to maternal teaching of reading and shared reading at preschool age? We expected that a child's emergent literacy skills would be positively related to the maternal home literacy activities. Also, we assumed that a belief in the importance of literacy readiness before school would be associated with the more frequent teaching of reading at home. Finally, the mother's positive beliefs and high expectations for her children's competences were expected to be related to more frequent literacy activities at home.

\section{Method}

\section{Participants}

The participants (1,880 children and their mothers) came from an extensive longitudinal study (AUTHORS), which is an ongoing investigation of children's academic 
development in family and school contexts. They were recruited from four Finnish municipalities (one in western Finland, one in central Finland, and two in eastern Finland). Parents gave written consent to their child's participation. With respect to children's language background, $98.9 \%$ of our sample spoke Finnish at home. Only 5\% of children were exposed to a home language other than Finnish, with only $1.1 \%(\mathrm{n}=16)$ of families not using Finnish as a spoken language at home at all (Sikiö et al., 2016, 2018). Thus, the sample was highly homogeneous in ethnic and cultural background, which is typical of the school population in Finland. It can be considered representative of children living in Finland, as it was comparable to the general population in terms of parental educational level (Statistics Finland, 2007): $6 \%$ had completed no more than the nine years of compulsory education (6\% in the general population), $30 \%$ had completed some kind of further education (30\% in the general population), $36 \%$ had a Bachelor's degree or vocational college degree (35\% in the general population), and $28 \%$ had a Master's degree or higher (29\% in the general population).

Children. The children (age in months: $M=73.89, S D=3.52$, at a baseline in September) were followed across 5 time-points: the beginning of preschool (September; $\mathrm{N}=$ 1,867; $\mathrm{T} 1$ ), the end of preschool (April; $\mathrm{N}=1,839$; T2), the beginning of Year 1 (September; $\mathrm{N}=2,022 ; \mathrm{T} 3$ ), the end of Year 1 (April; $\mathrm{N}=2,051 ; \mathrm{T} 4)$, and the end of Year 2 (April; $\mathrm{N}=$ 2,005; T5). In preschool, children were tested on their emergent literacy and language skills, such as phonological skills (T1 and T2), letter knowledge (T1 and T2) and vocabulary (T2). Trained researchers administered individual tests in preschool. A total of 28 children dropped out of the study between the first and second measurement points because their families moved away. In primary school, literacy and language skills, such as word reading fluency (T3, T4, and T5), listening comprehension (T4 and T5), sentence reading fluency (T4 and T5), and vocabulary (T5), were tested. The children's skills were assessed in group situations 
in classrooms, by tests administered by trained researchers, with the exception of the vocabulary tests. A vocabulary test (T5) was administered individually for only a part of the sample. The increase in the sample size in Years 1 and 2 was due to the new structure of the classes in Year 1, when, for example, new children who had not attended preschool entered Year 1 classes. All the new classmates were also assessed in Year 2. No systematic differences were detected between children who had joined the study after preschool and those whose data was available from their preschool year.

Mothers. Out of the 1,880 mothers who allowed their children to participate in the study, a total of 1,568 (83.40\%) filled in questionnaires in the spring of the preschool year (T2). The mothers' ages ranged from 24 to $55(M=37.37, S D=5.21)$. A total of $76.6 \%$ of the children were from families with two parents; $8.3 \%$ of the children were from families where the mother or father was living with his or her new spouse and their children; $13.1 \%$ of the children were living with a single mother; and $2 \%$ in families with shared parenthood after divorce or separation. The number of children in a family ranged from one to eleven $(M$ $=2.45, S D=1.17)$. A total of $24.5 \%$ of the mothers were unemployed.

\section{Measures}

\section{Mothers' Questionnaire in Preschool (T2)}

Home Literacy Activities. The questionnaire on mothers' home literacy activities was based on the work of Sénéchal and her colleagues (Sénéchal, 2006; Sénéchal et al., 1998; Sénéchal \& LeFevre, 2002, 2014), and has been used before in the Finnish context (Silinskas et al., 2010, 2012). The questions were capturing both current and retrospective frequency of maternal home literacy activities.

The teaching of reading was measured by asking mothers to answer the question, How often do you teach/Have you previously taught your child to read? on a five-point scale $(1=$ not at all/very rarely to $5=$ very often/daily). The mean value was 2.23 , with a mode value of 
2 (seldom; 37.5\%). In another Finnish study (Aunola \& Nurmi, 2007), the parental teaching of reading in Year 1 correlated .28 with daily parental reports on reading-related teaching.

To measure shared reading mothers were asked to answer the question, How often do you read books to your child or together with your child? on a five-point scale $(1=$ less than once $a$ week, 2 = 1-3 times $a$ week, 3 = 4-6 times $a$ week, $4=$ once a day, and 5 = more than once a day). We obtained a mean score of 2.91 with a mode value of four (once a day $=$ 32.6\%). In another Finnish study (Lerkkanen, in press), a five-item measure of shared reading $(\alpha=.75)$ related to phoneme awareness $(r=.12)$ and letter knowledge $(r=.10)$, suggesting a somewhat comparable predictive validity to the results of our current study (see correlations in Table 2).

Maternal beliefs and expectations were measured for four types of maternal beliefs and expectations concerning children's schooling and competence: (1) The importance of reading and writing readiness was measured by a single question: How important do you consider the following skills and their teaching in preschool education to be? Literacy and writing readiness (nursery rhymes, linguistic games, letters). It was measured on a five-point scale $(1=$ not really important, $2=$ important to some extent, $3=$ quite important, $4=$ important, and $5=$ very important). (2) The child's talent in reading and writing was measured by a single question: To what extent does your child have a natural talent for preschool assignments concerning reading and writing? Answers were given on a four-point scale $(1=$ not very much, $2=$ quite a lot, $3=$ a lot, $4=$ very much $)$. (3) The child's effort in reading and writing was measured by a single question: To what extent does your child have to try to manage well in the preschool assignments concerning reading and writing? Answers were given on a four-point scale $(1=$ not very much, $2=$ quite a lot, $3=$ a lot, $4=$ very much $)$. Finally, (4) expectations for the child's performance were assessed by three items: How well is your child working in preschool? How well is your child doing in preschool? and How well 
do you think your child will fare later at school? Answers were given on a four-point scale (1 $=$ not very well, $2=$ quite well, $3=$ well, $4=$ very well $)$. The internal consistency (Cronbach's alpha) was .82. The items were modified from questionnaires used by Frome and Eccles (1998). Similar items have earlier been used in the Finnish context (Aunola et al., 2002).

\section{Children's Tests (T1-T5)}

Phonological awareness (T1 and T2). Phonological awareness was measured individually in preschool by an initial phoneme identification test from the ARMI test battery (Lerkkanen, Poikkeus, \& Ketonen, 2006). The main task for the children was to identify the object in a set of 4 pictures that had the same first sound as the sound pronounced by the tester. The children's score was the number of correct responses out of a total of 10.

Letter knowledge (T1, T2, and T3). In preschool (T1 and T2), during individual testing, children were asked to name 29 uppercase letters from the ARMI test battery (Lerkkanen et al., 2006). At the beginning of Year 1 (T3), children were tested in group situations. Instead of naming the shown letter, they had to write down the letter that the test administrator said.

Vocabulary (T2 and T5). A 30-item shortened version of the Peabody Picture Vocabulary Test-Revised (PPVT-R, Form L; Dunn \& Dunn, 1981) was used to measure receptive vocabulary in preschool and Year 2. In PPVT, the children selected which one of four pictures correctly represented a spoken word. The items for the shortened version were selected on the basis of data from the full-scale administration of the PPVT-R in the Jyväskylä Longitudinal Study of Dyslexia (see Lyytinen et al., 2004). The children's scores were the number of correct responses (max. 30).

Word reading fluency (T3, T4, and T5). A group-administered test was used to assess word reading fluency, which is a subtest of the nationally normed reading test battery (ALLU; Lindeman, 1998). Each of the 80 items consisted of a picture with four 
phonologically similar words attached to it. The child silently read the four words and then drew a line connecting the picture with the word semantically matching it. The score was the number of correct answers within a 2-minute time limit. Because of the nature of this timelimited test, the score reflects both the child's fluency in reading the stimulus words and accuracy in making the correct choice from among the alternatives.

Listening comprehension (T4 and T5). In Year 1 (T4), a group-administered test developed at the Centre for Learning Research at the University of Turku (Finland) was used to assess listening comprehension. A story consisting of a total of 130 words was read aloud twice to the children in a classroom setting. There were six multiple-choice questions based on the text. Pictures accompanied the questions. The children selected the picture that would best fit the story. Two points were given for the picture that best fitted the story (best match), and one point was awarded for the picture that could be considered suitable as well (second best match) $(\max .=12)$. In Year $2(\mathrm{~T} 5)$, a group-administered test was adapted from a subtest of the nationally normed reading test battery (ALLU; Lindeman, 1998). A story 135 words long was read aloud twice to the children in the classroom setting. The tester then read the questions and the four alternative responses. The children selected the picture that would best fit the story. This time, 1 point was given for each correct answer $(\max .=8)$.

Sentence reading fluency (T4 and T5). The Test of Sentence Reading Efficiency (TOSRE; Wagner, Torgesen, Rashotte, \& Pearson, 2010) was used to assess sentence reading fluency. The children silently read 60 sentences (e.g., Apples are blue), and then, one at a time, answered whether the sentence was true or false. The score was the number of correct answers $(\max .=60)$ within a 3-minute time limit.

\section{Analysis Strategy}

To answer our first research question concerning associations between home literacy activities and children's literacy and language skills, we constructed a path model (Figure 1). 
In this model, each literacy and language outcome was regressed on the child outcomes from the previous time-point (stability). In addition, for language measures, we allowed vocabulary at $\mathrm{T} 2$ to predict listening comprehension at the end of Year 1 (T4) and vocabulary at the end of Year 2 (T5). This was done to account for the previous levels of oral language related skills. Concurrent correlations between all study variables within the same time-point were specified, as were cross-lagged paths between skills at subsequent time-points. Maternal home literacy activities — the teaching of reading and shared reading —were entered into the model to be predicted by children's skills at the beginning of preschool (T1), to be concurrently correlated to all children's skills at the end of preschool (T2), and to predict all subsequent children's skills in Years 1 and 2 (T3-T5). Note that maternal teaching activities were measured only once during preschool year (at T2), therefore they were correlated with T2 measures, predicted by T1 measures and further predicted T3-T5 measures. As the final step, we added child age, child gender, and maternal education as controls (see descriptives of the control variables in Table 1 and correlations with all study variables in Table 2).

To answer our second research question concerning the association between maternal beliefs and their home literacy activities, we entered maternal beliefs in our previously constructed model (Figure 1). Because maternal beliefs were measured at the same time as maternal home literacy practices, we correlated maternal beliefs with the maternal home literacy activities and children's skills at the same time, the end of preschool (T2). Within the context of the previously developed model (Figure 1), we also specified additional paths in our model, that is, maternal beliefs (T2) were predicted by children's phonological awareness and letter knowledge (T1).

The data were analysed using the Mplus statistical package (Version 7.3; Muthén \& Muthén, 1998-2010). Preliminary examination of the data showed that the proportion of missing data for all study variables ranged from $9.1 \%$ to $31.4 \%(M=21.65 \%, S D=8.69 \%)$. 
The data were not missing-completely-at-random (MCAR), Little's (1988) MCAR test: $\chi^{2}$ $(1239)=1951.81, p<.001$. Thus, missingness-at-random (MAR, not MCAR) was assumed, and we continued with the standard FIML procedure (full-information maximum likelihood for missing data). This missing data method uses all the data that are available in order to estimate the model without imputing data. The distributions of some of the variables were skewed; thus, the model parameters were estimated using the MLR estimator (maximum likelihood with robust standard errors), which is implemented in Mplus. The MLR estimator produces standard errors and chi-square test statistics for missing data with non-normal outcomes and non-independent observations by means of a sandwich estimator.

All the presented models were trimmed (i.e., all non-significant paths and correlations/covariances with $p<.10$ were fixed to zero). Model fit was examined using five model-fit statistics: the chi-square $\left(\chi^{2}\right)$, the Comparative Fit Index (CFI), Tucker-Lewis Index $(T L I)$, root mean square error of approximation (RMSEA), and standardized root mean square residual $(S R M R)$. Non-significant $\chi^{2}, C F I$ and $T L I$ values above .95, a RMSEA value below .06 and a SRMR value below .08 indicate good model fit (Hu \& Bentler, 1999; Muthén \& Muthén, 1998-2010). CFI and TLI values below .90 and RMSEA and SRMR values above .10 are indications of poor model fit (Kline, 2005).

Because of the nested structure of the dataset (children nested within classrooms), the intra-class correlations (ICCs) were investigated to estimate the effect of membership in a certain preschool group. The $I C C$ is the estimate of the proportion of the total score variance that is attributable to an individual's membership in a particular class. Average cluster size was 10.68. As also shown in Table 1, the ICC s across all preschool measures varied from .01 to .05 (from $p>.05$ to $p<.001$ ). Because some of the ICCs were statistically significant, albeit very small, all standard errors in the models were corrected accordingly with the TYPE $=$ COMPLEX option provided by Mplus. The COMPLEX function computes estimated 
standard errors and a chi-square test of model fit taking into account non-independence of observations due to cluster sampling (i.e., accounts for the nesting of multiple children in each class).

\section{Results}

\section{The Home Literacy Model: A Longitudinal Path Model}

To answer our first research question, concerning testing the Home Literacy Model in Finnish, we estimated and trimmed the longitudinal path model (Figure 1). The model fit was good: $\chi^{2}(66)=450.45, p<.001, C F I=.96, \mathrm{TLI}=.93, R M S E A=.06, S R M R=.05$. Note that correlations between error terms between concurrent measures were included in the model and described in the captions of Figure 1 (e.g., correlation between teaching of reading and shared reading, $r=.09, p<.001$ ), although they were not depicted in the figure itself for clarity of presentation. The results showed (Figure 1), first, that the teaching of reading positively predicted letter knowledge and marginally word reading fluency at the beginning of Year 1 (T3), as well as sentence reading fluency at the end of Year 2 (T5). Shared reading positively predicted children's listening comprehension and vocabulary. It also positively predicted sentence reading fluency (marginally) at the end of Year 2 (T5). Somewhat unexpectedly, shared reading negatively predicted word reading fluency at the end of Year 1 (T4). However, the zero order correlation (Table 2) between these variables was close to zero $(r=-.02, p>.10)$.

\section{Correlates of Home Literacy Activities}

To answer our second research question, maternal beliefs were entered to our previously constructed model in such a way that they would concurrently correlate with home literacy practices and skills (T2) and would be predicted by previous skills (T1). Although the results concerning maternal beliefs were estimated in the context of the complex model presented in Figure 1, those results were not presented in the figure for reasons of clarity. The results 
concerning our second research question showed, firstly, that letter knowledge at the beginning of preschool (T1) positively predicted the teaching of reading $(\beta=.19, p<.001)$ and shared reading $(\beta=.15, p<.001)$ at the end of preschool (T2) (the paths identical to the paths presented in Figure 1). Secondly, the results (correlations not depicted in the figure) revealed that maternal beliefs and expectations were positively related to mothers' teaching activities, but not to shared reading activities. That is, if a mother considered literacy and writing readiness important in preschool $(r=.16, p<.001)$, felt strongly that her child had a natural talent for reading and writing $(r=.14, p<.001)$, and had high confidence in her children's success at school (performance) $(r=.12, p<.001)$, she was also more likely to teach her child reading in preschool. Maternal beliefs were unrelated to the maternal shared reading with a child.

\section{Additional Analyses}

Finally, we controlled the previously specified model (Figure 1) for child age, gender, and maternal education. The three control variables were specified to predict all study variables. The results reported previously did not change. However, new results emerged on the connection between control variables and the main study variables. In general, across all time points, control variables had a similar pattern of relationship with children's language and literacy skills: Older children, girls, and children with more educated mothers were more likely to score higher in language and literacy skills. Concerning maternal home literacy activities, girls were more likely to be exposed to the teaching of reading than boys $(\beta=-.09$, $p<.01)$. Also, more highly educated mothers were more likely to engage in shared reading activities $(\beta=.19, p<.001)$.

\section{Discussion}

The present study tested the Home Literacy Model in the highly transparent Finnish language. After controlling for previous levels of children's language and literacy skills, our 
results showed that shared reading predicted oral language skills in Year 1 and Year 2 (vocabulary and listening comprehension), whereas the maternal teaching of reading at preschool age showed a relatively weak, albeit statistically significant, contribution to written language skills in Year 1 (letter knowledge and word reading fluency). In Year 2, both the teaching of reading and shared reading were additional predictors of sentence reading fluency. These findings suggest that the teaching of reading in the preschool year is not necessary for good reading development in a highly transparent language. One possible explanation for this result may be that most children find it quick and relatively easy to learn to read due to the combination of the easy orthography and effective phonics instruction in schools. On the other hand, our results suggest that shared reading is important for the development of listening comprehension and vocabulary, which both feed into sentence reading fluency. Another important contribution of the present study to the literature was the identification of the correlates of maternal home literacy activities. We found that high levels of children's letter knowledge were related to high levels of maternal teaching of reading and shared reading. Also, maternal beliefs about the importance of children's literacy and writing readiness before Year 1, their evaluations of their children's performance in reading and writing tasks, and their expectations for their child's overall school performance were associated with the frequency of teaching their child to read.

\section{The Home Literacy Model in a Highly Transparent Orthography}

Our first research question concerned the extent to which the hypothesized Home Literacy Model (Sénéchal \& LeFevre, 2002, 2014) holds also in the highly transparent Finnish language. Our results showed that teaching reading was related to letter knowledge and predicted letter knowledge and word reading fluency in Year 1, and sentence reading fluency in Year 2, but these effects were weak. Such weak results could be expected, given the transparent orthography of the Finnish language. This high transparency makes reading 
acquisition a rapid process: One third of Finnish children learn to decode before Year 1 (e.g., Lerkkanen et al., 2004; Silinskas et al., 2010), and the majority learn to decode accurately during the first half of Year 1 (Lerkkanen et al., 2004). Living in this kind of language environment is likely not to engage mothers in teaching-related activities. Moreover, any effect of their teaching of reading during preschool is likely to fade out once children are exposed to the explicit teaching of reading by their Year 1 teachers.

Shared reading, as expected (Hood et al., 2008; Sénéchal, 2006; Sénéchal \& LeFevre, $2002,2014)$, showed the strongest relation to oral language skills, that is, concurrent vocabulary, vocabulary two years later in Year 2, listening comprehension in Years 1 and 2, and sentence reading fluency in Year 2. We found that shared reading related to oral language skills before the transition to Year 1 . Thus, our results confirm that shared reading is important for the development of listening comprehension and vocabulary, which both feed into sentence reading fluency (i.e., Simple View of Reading; Gough \& Tunmer, 1986; Kirby \& Savage, 2008; Stuart, Stainthorp, \& Snowling, 2008; see Torppa et al., 2016, for the Finnish context). According to this view, we can anticipate that the effect will be even stronger beyond Year 2, when the children progress in their reading skills. In Year 2, sentence reading fluency is still dependent on a number of basic reading skills; many children have not yet reached a level of automaticity in basic decoding to the degree that would allow them to free up cognitive resources for comprehension.

Overall, our results add to the literature by showing that the Home Literacy Model is important in explaining the relation between maternal home literacy activities during preschool and children's literacy and language also in highly transparent orthographies, such as Finnish. However, the effects of the maternal teaching of reading in a Finnish-speaking sample are small in comparison with those demonstrated in opaque (Sénéchal, 2006; Sénéchal et al., 1998; Sénéchal \& LeFevre, 2002) and less transparent orthographies (Farver 
et al., 2013; Lehrl et al., 2013; Manolitsis et al., 2011, 2013; Niklas \& Schneider, 2013, 2017). Also, the effect of the maternal teaching of reading on reading decoding and fluency seems to be fading by the end of Year 1 (Sénéchal \& LeFevre, 2014; Silinskas et al., 2012). In contrast, the effect of shared reading was found to be important for oral language skills (vocabulary and listening comprehension) at all the time points at which these skills were measured. Both the teaching of reading and shared reading were weakly related to sentence reading fluency at the end of Year 2, by which time every child is expected to have learnt to read relatively fluently. Also worth noting is the fact that the relations reported above were found to be significant even after controlling for the previous level of the same skill and control variables, and when a complex pattern of associations between children's literacy and language measures was estimated in the same model.

\section{Correlates of Home Literacy Activities}

We also investigated what factors might affect the mother's teaching of reading and shared reading in the preschool year. Two types of factors of maternal engagement in home literacy activities were considered: children's emergent literacy skills (Silinskas et al., 2010) and maternal beliefs and expectations about their children's schooling and competences (Aunola et al., 2002; Burgess et al., 2002; Kluczniok et al., 2013; Martini \& Sénéchal, 2012; Roberts et al., 2005; Sénéchal \& LeFevre, 2014; Skwarchuk et al., 2014). The results showed that it was letter knowledge in particular that related to the increased levels of subsequent maternal teaching of reading and shared reading. This result is in line with some previous research showing that children's letter knowledge can signal to their mothers that a child is ready to be engaged in more advanced literacy activities with his or her parents (Silinskas et al., 2010). However, our result does not indicate the onset of such an association, as it is possible that the relations of emergent literacy skills to parental responses (home literacy activities) start emerging much earlier than the preschool year. By this time, many children 
already know most of the letters, and they might already have been informally taught for several years by their parents, siblings or friends (Torppa et al., 2006, 2007). Another explanation for the relationship between letter knowledge and the parental teaching of reading and shared reading could be to do with children's higher interest and motivation to learn (Kikas et al., 2016; Silinskas et al., 2019). Thus, it is possible that the teaching of reading at home can be child initiated active process (Green, Walker, Hoover-Dempsey, \& Sandler, 2007; Hoover-Dempsey \& Sandler, 1995). At preschool age, children are generally interested in joint activities with their parents and parents typically select activities depending on their child's interests; they might therefore naturally end up teaching their children reading or engaging in shared reading activities.

Another possible source of parental home literacy involvement is the parents' own beliefs and expectations about children's schooling and competences. The present study found that parental beliefs related significantly only to the maternal teaching of reading, but not to maternal shared reading. The present study showed that maternal beliefs concerning children's school readiness in literacy were related to their own increased teaching behaviours (Martini \& Sénéchal, 2012; Sénéchal \& LeFevre, 2014; Skwarchuk et al., 2014). This result is interesting in the light of the widespread belief that children should not be taught reading before school because they will quickly learn it during Year 1. However, at a mean level, mothers think that literacy skills are "quite important" to "important" before entering Year 1. Possibly because of that belief, mothers also engage in more frequent teaching activities, although the design of our study leaves room for alternative interpretations of the direction of this association.

Another set of beliefs concerned evaluations of their children's talent and effort in reading and writing tasks (Aunola et al., 2002; Frome \& Eccles, 1998; Stephenson et al., 2008), as well as their expectations for their children's performance and school success in 
general (Aunola et al., 2002; Mägi et al., 2011; Stephenson et al., 2008; Storch \& Whitehurst, 2001). Our results suggest that if a mother felt sure that her child had a talent for reading and writing and had great confidence in her child's school performance, then she was more likely to teach her child reading during preschool. The relation of both of these beliefs to the more frequent teaching of reading may point to the higher emergent literacy skills of these children (Aunola et al., 2002; also found in this study), and arguably to the child's greater interest in reading. Alternatively, the results of the present study may indicate that the more a mother invests in teaching her child, the more she starts to hope for and expect her child's success (Frome \& Eccles, 1998).

The fact that shared reading did not relate to maternal beliefs and expectations may indicate that in Finnish culture parents traditionally read with their child. According to our study, for example, around one third of mothers do so once a day. Moreover, lack of association of parental beliefs and expectations with informal literacy activities was also documented in the previous research (Skwarchuk et al., 2014).

\section{Limitations}

Some limitations need to be taken into account when generalizing the results of this study. First of all, most of the maternal variables, including parental home literacy activities and beliefs, were measured by a single item. Although some previous studies have used a similar procedure for measuring the teaching of reading (Silinskas et al., 2010, 2012; Torppa et al., 2006, 2007), shared reading (see Bus et al., 1995, for a review) and maternal beliefs (Aunola et al., 2002), single-item measures are not the best way of measuring maternal home literacy activities and beliefs. For instance, the teaching of reading can cover a wider range of of activities, such as teaching the alphabet or joint spelling (Aram \& Levin, 2002; Levin \& Aram, 2005; Reese, Sparks, \& Leyva, 2010). As for shared reading, whilst the frequency of shared reading is an important aspect of the HLE, other aspects should be considered as well 
(Niklas, Nguyen, Cloney, Tayler, \& Adams, 2016; Tayler et al., 2015). Some studies have used checklists to measure shared reading (Cunningham \& Stanovich, 1990; Davidse et al., 2011; Sénéchal \& LeFevre, 2014). Much could also be gained by including observations of maternal teaching and shared reading at home (Mussar et al., 2018). Using single items does not make it possible to estimate the reliability of the measure. Had we measured maternal home literacy activities by means of more or different items (i.e., more reliably), the associations between maternal variables and children's skills could have been stronger. Thus, developing and using more calibrated items remains a challenge of our future research. Secondly, in the present study we used self-report measures of the teaching of reading and shared reading, which raises the issue of social desirability. Although similar self-report measures have often been used in previous research, for more reliable and optimal evaluations, future studies should also include observational measures or in-depth interviews. Thirdly, some of our child measures suffered from relatively low reliability and skewed distributions. Having stronger and purer measures, particularly for vocabulary and listening comprehension, could have increased the power of identifying significant and meaningful paths in the model. Fourthly, although our study was longitudinal in that it followed children across five time-points, maternal reports were assessed only once. This means that no causality between children's skills and maternal factors can be assumed. For instance, although our tentative interpretation suggests that maternal beliefs trigger their practices, the causality could work in the other direction. Also, earlier home literacy activities (e.g., at the beginning of preschool or even earlier) might have an impact on, for instance, maternal beliefs and children's early letter knowledge (Rodriguez \& Tamis-LeMonda, 2011). Fifthly, for vocabulary in Year 2, only part of the sample (i.e., 578 children) was tested, and therefore we ran a sensitivity analysis_-our final longitudinal path model. Although no significant deviations were found from previous results in terms of the magnitude of the coefficients, 
many small coefficients obviously lost their statistical significance due to the crucial decrease in statistical power. Finally, although we found somewhat weaker associations among Finnish children than those learning to read in less transparent orthographies, the weaker association may not necessarily result from the context, such as differences in orthography or in reading development. It is possible that other characteristics that differentiate the samples and studies, such as the measures used, cause the difference. We need direct cross-cultural comparison studies that control for the key factors influencing reading development to be able to establish the reasons for the differences in relations between home literacy practices and reading skills across contexts.

\section{Conclusions}

The present study makes two important contributions to the literature. First, our study provides evidence of the applicability of the Home Literacy Model in the context of a highly transparent orthography by replicating the results obtained in opaque orthographies, such as English or French. Our study showed that the home teaching of reading at preschool age weakly but significantly predicted children's emergent literacy (letter knowledge, word reading fluency) in primary school, whereas shared reading predicted children's oral language skills, such as vocabulary and listening comprehension, in primary school. Second, our results provide new insights into what motivates mothers to engage in teaching reading and shared reading activities in the preschool year: Early letter knowledge relates to both the teaching of reading and shared reading, while maternal beliefs and expectations about their children's schooling and competence relate to their more frequent engagement in teaching reading. 


\section{References}

Aram, D., \& Levin, I. (2002). Mother-child joint writing and storybook reading: Relations with literacy among low SES kindergartners. Merrill-Palmer Quarterly (1982-), 202-224. Aunola, K., \& Nurmi, J.-E. (2007). VALO [The Light Study: Parents, teachers, and children's learning study]. Unpublished raw data, University of Jyväskylä, Finland.

Aunola, K., Nurmi, J. E., Niemi, P., Lerkkanen, M. K., \& Rasku-Puttonen, H. (2002). Developmental dynamics of achievement strategies, reading performance, and parental beliefs. Reading Research Quarterly, 37, 310-327.

Burgess, S., Hecht, S. \& Lonigan, C. (2002). Relations of the home literacy environment (HLE) to the development of reading-related abilities: A one-year longitudinal study. Reading Research Quarterly, 37, 408-426.

Bus, A. G., van IJzendoorn, M. H., \& Pellegrini, A. D. (1995). Joint book reading makes for success in learning to read: a meta-analysis on intergenerational transmission of literacy. Review of Educational Research, 65, 1-21.

Cunningham, A. E., \& Stanovich, K. E. (1990). Assessing print exposure and orthographic processing skill in children: A quick measure of reading experience. Journal of Educational Psychology, 82, 733-740.

Davidse, N. J., de Jong, M. T., Bus, A. G., Huijbregts, S. C. J., \& Swaab, H. (2011). Cognitive and environmental predictors of early literacy skills. Reading and Writing: An Interdisciplinary Journal, 24, 395-412.

Davis-Kean, P. E. (2005). The influence of parent education and family income on child achievement: the indirect role of parental expectations and the home environment. Journal of Family Psychology, 19, 294-304.

Dunn, L. M., \& Dunn, L. M. (1981). Peabody Picture Vocabulary Test-Revised. Circle Pines, MN: American Guidance Service. 
Farver, J. M., Xu, Y., Lonigan, C. J., \& Eppe, S. (2013). The home literacy environment and Latino Head Start children's emergent literacy skills. Developmental Psychology, 49, 775791.

Frome, P. M., \& Eccles, J. S. (1998). Parents' influence on children's achievement-related perceptions. Journal of Personality and Social Psychology, 74, 435-452.

Gough, P. B., \& Tunmer, W. E. (1986). Decoding, reading, and reading disability. RASE: Remedial \& Special Education, 7, 6-10.

Green, C. L., Walker, J. M. T., Hoover-Dempsey, K. V., \& Sandler, H. M. (2007). Parents' motivations for involvement in children's education: An empirical test of a theoretical model of parental involvement. Journal of Educational Psychology, 99, 535-544.

Hood, M., Conlon, E., \& Andrews, G. (2008). Preschool home literacy practices and children's literacy development: A longitudinal analysis. Journal of Educational Psychology, 100, 252-271.

Hoover-Dempsey, K. V., \& Sandler, H. M. (1995). Parental involvement in children's education: Why does it make a difference? Teacher's College Record, 97, 310-331.

Hu, L. -T., \& Bentler, P. (1999). Cutoff criteria for fit indices in covariance structure analysis: Conventional criteria versus new alternatives. Structural Equation Modeling, 6, $1-55$.

Kirby, J. R., \& Savage, R. S. (2008). Can the simple view deal with the complexities of reading? Literacy, 42, 75-82.

Kline, R. B. (2005). Principles and practice of structural equation modeling (2nd ed.). New York, NY: Guilford Press.

Kluczniok, K., Lehrl, S., Kuger, S. \& Rossbach, H.-G. (2013). Quality of the home learning environment during preschool age-Domains and contextual conditions. European Early Childhood Education Research Journal, 21, 420-438. 
Lehrl, S., Ebert, S. \& Roßbach, H.-G. (2013). Facets of preschoolers' home literacy environments: What contributes to reading literacy in primary school? In M. Pfost, C. Artelt \& S. Weinert (Eds.), The development of reading literacy from early childhood to adolescence. Empirical findings from the Bamberg BiKS longitudinal studies (p. 35-62). Bamberg: University of Bamberg Press.

Lerkkanen, M.-K. (in press). Early language and literacy development in the Finnish context. In D. Whitebread, V. Grau, K. Kumpulainen, M.M. McClelland, D. Pino-Pasternak, \& N.E. Perry (Eds.). The Sage Handbook of Developmental Psychology and Early Childhood Education. London: Sage.

Lerkkanen, M.-K., Poikkeus, A.-M., \& Ketonen, R. (2006). ARMI - Luku- ja kirjoitustaidon arviointimateriaali 1. luokalle. [ARMI - A tool for assessing reading and writing skills in first grade]. Helsinki: WSOY.

Lerkkanen, M.-K., Rasku-Puttonen, H., Aunola, K., \& Nurmi, J.-E. (2004). Predicting reading performance during the first and the second year of primary school. British Educational Research Journal, 30, 67-92.

Levin, I., \& Aram, D. (2005). Children's names contribute to early literacy: A linguistic and social perspective. In D. D. Ravid \& H. B.-Z. Shyldkrot (Eds.), Perspectives on language and language development (pp. 219-239). Boston, MA: Springer.

Levin, I., Levy-Shiff, R., Applebaum-Peled, T., Katz, I., Komar, M., \& Meiran, N. (1997). Antecedents and consequences of maternal involvement in children's homework: A longitudinal analysis. Journal of Applied Developmental Psychology, 18, 207-227.

Levy, B. A., Gong, Z., Hessels, S., Evans, M., \& Jared, D. (2006). Understanding print: Early reading development and the contributions of home literacy experiences. Journal of Experimental Child Psychology, 93, 63-93. 
Lindeman, J. (1998). Allu - Ala-asteen lukutesti. [Reading test for primary school]. Turku, Finland: University of Turku.

Little, R. J. A. (1988). A test of missing completely at random for multivariate data with missing values. Journal of the American Statistical Association, 83, 1198-1202.

Lyytinen, H., Aro, M., Eklund, K., Erskine, J., Guttorm, T. K., Laakso, M.-L., ... Torppa, M. (2004). The development of children at familial risk for dyslexia: Birth to school age. Annals of Dyslexia, 54, 184-220.

Mägi, K., Lerkkanen, M. K., Poikkeus, A. M., Rasku-Puttonen, H., \& Nurmi, J. E. (2011). The cross-lagged relations between children's academic skill development, taskavoidance, and parental beliefs about success. Learning and Instruction, 21, 664-675.

Manolitsis, G., Georgiou, G., \& Parrila, R. (2011). Revisiting the home literacy model of reading development in an orthographically consistent language. Learning and Instruction, 21, 496-505.

Manolitsis, G., Georgiou, G. K., \& Tziraki, N. (2013). Examining the effects of home literacy and numeracy environment on early reading and math acquisition. Early Childhood Research Quarterly, 28, 692-703.

Martini, F., \& Sénéchal, M. (2012). Learning literacy skills at home: Parent teaching, expectations, and child interest. Canadian Journal of Behavioural Science, 44, 210-221.

Muthén, L.K., \& Muthén, B.O. (1998-2010). Mplus user's guide (6th ed.). Los Angeles, CA: Muthén \& Muthén.

Mussar, R., Celebi, H., Bildfeld, A., \& Sénéchal, M. (2018, May). Young Children's Construction of Vocabulary Knowledge. Paper presented in the symposium entitled On Interactions that Enhance Language Development: Examining the Role of Parents, Teachers, and Technology at the annual meeting of the presented at the annual meeting of the Jean Piaget Society, Amsterdam, Netherlands. 
Niklas, F., Nguyen, C., Cloney, D., Tayler, C., \& Adams, R. (2016). Self-report measures of the home learning environment in large scale research: Measurement properties and associations with key developmental outcomes. Learning Environments Research, 19, 181-202.

Niklas, F., \& Schneider, W. (2013). Home literacy environment and the beginning of reading and spelling. Contemporary Educational Psychology, 38, 40-50.

Niklas, F., \& Schneider, W. (2017). Home learning environment and development of child competencies from kindergarten until the end of elementary school. Contemporary Educational Psychology, 49, 263-274.

Pomerantz, E. M., \& Eaton, M. M. (2001). Maternal intrusive support in the academic context: Transactional socialization processes. Developmental Psychology, 37, 174-186.

Reese, E., Sparks, A., \& Leyva, D. (2010). A review of parent interventions for preschool children's language and emergent literacy. Journal of Early Childhood Literacy, 10, 97117.

Roberts, J., Jurgens, J. \& Burchinal, M. (2005). The role of home literacy practices in preschool children's language and emergent literacy skills. Journal of Speech, Language, and Hearing Research, 48, 345-359.

Rodriguez, E. T., \& Tamis-LeMonda, C. S. (2011). Trajectories of the home learning environment across the first 5 years: Associations with children's vocabulary and literacy skills at prekindergarten. Child Development, 82, 1058-1075.

Scarborough, H. S., \& Dobrich, W. (1994). On the efficacy of reading to preschoolers. Developmental review, 14, 245-302.

Scarr, S., \& McCartney, K. (1983). How people make their own environments: A theory of genotype $\rightarrow$ environment effects. Child Development, 54, 424-435. 
Sénéchal, M. (2006). Testing the home literacy model: Parent involvement in kindergarten is differentially related to grade 4 reading comprehension, fluency, spelling, and reading for pleasure. Scientific Studies of Reading, 10, 59-87.

Sénéchal, M., \& LeFevre, J.-A. (2002). Parental involvement in the development of children's reading skills: A five-year longitudinal study. Child Development, 73, 445-460.

Sénéchal, M., \& LeFevre, J.-A. (2014). Continuity and change in the home literacy environment as predictors of growth in vocabulary and reading. Child development, 85, $1552-1568$.

Sénéchal, M., LeFevre, J.-A., Thomas, E. M., \& Daley, K. E. (1998). Differential effects of home literacy experiences on the development of oral and written language. Reading Research Quarterly, 33, 96-116.

Seymour, P. H. K., Aro, M., \& Erskine, J. M. (2003). Foundation literacy acquisition in European orthographies. British Journal of Psychology, 94, 143-174.

Silinskas, G., Dietrich, J., Pakarinen, E., Kiuru, N., Aunola, K., Lerkkanen, M.-K., Hirvonen, R., Muotka, J., \& Nurmi, J.-E. (2015). Children evoke similar affective and instructional responses from their teachers and mothers. International Journal of Behavioral Development, 39, 432-444.

Silinskas, G., Leppänen, U., Aunola, K., Parrila, R., \& Nurmi, J.-E. (2010a). Predictors of mothers' and fathers' teaching of reading and mathematics in kindergarten and grade 1. Learning and Instruction, 20, 61-71.

Silinskas, G., Lerkkanen, M. K., Tolvanen, A., Niemi, P., Poikkeus, A. M., \& Nurmi, J. E. (2012). The frequency of parents' reading-related activities at home and children's reading skills during kindergarten and Grade 1. Journal of Applied Developmental Psychology, 33, $302-310$. 
Silinskas, G., Kiuru, N., Tolvanen, A., Niemi, P., Lerkkanen, M.-K., \& Nurmi, J.-E. (2013). Maternal teaching of reading and children's reading skills in grade 1: Patterns and predictors of positive and negative associations. Learning and Individual Differences, 27, $54-66$.

Silinskas, G., Parrila, R., Lerkkanen, M. K., Poikkeus, A. M., Niemi, P., \& Nurmi, J. E. (2010b). Mothers' reading-related activities at home and learning to read during kindergarten. European Journal of Psychology of Education, 25, 243-264.

Skwarchuk, S.-L., Sowinski, C. \& LeFevre, J.-A. (2014). Formal and informal home learning activities in relation to children's early numeracy and literacy skills: The development of a home numeracy model. Journal of Experimental Child Psychology, 121, 63-84.

Soodla, P., Lerkkanen, M. K., Niemi, P., Kikas, E., Silinskas, G., \& Nurmi, J. E. (2015). Does early reading instruction promote the rate of acquisition? A comparison of two transparent orthographies. Learning and Instruction, 38, 14-23.

Statistics Finland. (2007). Statistical databases. Retrieved from http://www.stat.fi/tup/tilastotietokannat/index en.html

Stephenson, K. A., Parrila, R. K., Georgiou, G. K., \& Kirby, J. R. (2008). Effects of home literacy, parents' beliefs, and children's task-focused behavior on emergent literacy and word reading skills. Scientific Studies of Reading, 12, 24-50.

Stevenson, H. W., \& Newman, R. S. (1986). Long-term prediction of achievement and attitudes in mathematics and reading. Child Development, 57, 646-659.

Storch, S. A., \& Whitehurst, G. J. (2001). The role of family and home in the literacy development of children from low-income backgrounds. New Directions for Child and Adolescent Development, 92, 53-72.

Stuart, M., Stainthorp, R., \& Snowling, M. (2008). Literacy as a complex activity: Deconstructing the simple view of reading. Literacy, 42, 59-66. 
Tayler, C., Cloney, D., \& Niklas, F. (2015). A bird in the hand: Understanding the trajectories of development of young children and the need for action to improve outcomes. Australasian Journal of Early Childhood, 40, 51-60.

Torppa, M., Georgiou, G. K., Lerkkanen, M. K., Niemi, P., Poikkeus, A. M., \& Nurmi, J. E. (2016). Examining the simple view of reading in a transparent orthography: A longitudinal study from kindergarten to grade 3. Merrill-Palmer Quarterly, 62, 179-206.

Torppa, M., Poikkeus, A.-M., Laakso, M.-L., Eklund, K., \& Lyytinen, H. (2006). Predicting delayed letter name knowledge and its relation to grade 1 reading achievement in children with and without familial risk for dyslexia. Developmental Psychology, 42, 1128-1142.

Torppa, M., Tolvanen, A., Poikkeus, A-M. Eklund, K., Lerkkanen, M-K., Leskinen, E., \& Lyytinen, H. (2007). Reading development subtypes and their early characteristics. Annals of Dyslexia, 57, 3-32.

Wagner, R. K., Torgesen, J. K., Rashotte, C. A., \& Pearson, N. (2010). The test of silent reading efficiency and comprehension (TOSREC). Austin, TX: PRO-Ed.

Ziegler, J. C., Bertrand, D., Tóth, D., Csépe, V., Reis, A., Faísca, L., ... \& Blomert, L. (2010). Orthographic depth and its impact on universal predictors of reading: A cross-language investigation. Psychological Science, 21, 551-559.

Ziegler, J. C., \& Goswami, U. (2005). Reading acquisition, developmental dyslexia, and skilled reading across languages: A psycholinguistic grain size theory. Psychological bulletin, 131, 3-29. 